\title{
Penetration of Meropenem into Pneumonic Human Lung Tissue as Measured by In Vivo Microdialysis
}

\author{
Florian Tomaselli, ${ }^{1 *}$ Alfred Maier, ${ }^{2}$ Veronika Matzi, ${ }^{2}$ Freyja Maria Smolle-Jüttner, ${ }^{2}$ \\ and Peter Dittrich ${ }^{3}$ \\ Department of General, Thoracic and Vascular Surgery, KH der Elisabethinen, Linz, ${ }^{1}$ and Department \\ of Surgery, Division of Thoracic and Hyperbaric Surgery, University Medical School of Graz, ${ }^{2}$ and \\ Institute of Pharmacology and Toxicology, University of Graz, ${ }^{3}$ Graz, Austria
}

Received 15 April 2003/Returned for modification 7 September 2003/Accepted 5 December 2003

\begin{abstract}
Until recently, information on antibiotic pharmacokinetic properties in infected human lung tissue was limited. We therefore studied a microdialysis-based approach for measurement of the penetration of meropenem into the extracellular space fluid of human pneumonic lung parenchyma. The lung penetration of meropenem was determined for seven patients with pneumonia and metapneumonic pleural empyema treated by decortication. Intraoperatively, two microdialysis probes were inserted into pneumonic lung tissue and one was inserted into healthy skeletal muscle for reference values. Serum and microdialysis samples were collected at 20-min intervals for at least $8 \mathrm{~h}$ following a single intravenous dose of $1 \mathrm{~g}$ of meropenem. The maximum free interstitial concentration (mean and standard deviation) of meropenem in infected lung tissue was 11.4 \pm 10.9 $\mathrm{mg} / \mathrm{liter}$, and that in serum was $47.3 \pm 21.0 \mathrm{mg} / \mathrm{liter}$. The areas under the curve for infected lung tissue $(36.2$ $\pm 17.9 \mathrm{mg} \cdot \mathrm{h} / \mathrm{liter})$ and serum $(95.4 \pm 46.6 \mathrm{mg} \cdot \mathrm{h} / \mathrm{liter})$ revealed a significant difference. This technique enabled quasi-continuous tissue pharmacokinetic measurements of free, unbound antibiotic in pneumonic lung tissue of patients with pneumonia. The present data corroborate the use of meropenem in the treatment of lung infections caused by extracellular bacteria, demonstrating the excellent distribution profile for meropenem in the interstitial space of human pneumonic lung tissue.
\end{abstract}

Despite advances in antibiotic development, lower respiratory tract infections and their associated severe complications, such as metapneumonic empyema, are still major clinical problems (18). Appropriate antibiotic treatment is probably the most effective single measure for dealing with lower respiratory tract bacterial infections. Antibiotic selection should be based on a number of criteria, including suspected causative pathogens and their likely antibiotic susceptibility patterns, the intrinsic antibacterial activities of available drugs, clinical factors (such as length of hospitalization and previous antibiotic usage), and the pharmacokinetic properties of antibiotics.

Indeed, unless an antibiotic is able to both sufficiently penetrate the target site and maintain an appropriate concentration in the tissue, it may fail to be clinically effective despite the documented in vitro susceptibility of the involved pathogen (5). In addition to causing therapeutic failure, the combination of high in vitro antibiotic MICs for causative pathogens (20) and suboptimal target site antibiotic concentrations may trigger the emergence of bacterial resistance (17).

Various methods have been developed to quantify the process of penetration of antibiotics into lung tissue. Concentrations of antibiotics have been measured in sputum samples $(6$, $9,19,28$ ), bronchoscopically harvested biopsy specimens, and bronchoalveolar lavage fluids $(15,32)$. More sophisticated approaches include the determination of antibiotic concentrations in epithelial lining fluid $(4,35)$ or in alveolar macro-

\footnotetext{
* Corresponding author. Mailing address: Department of General, Thoracic and Vascular Surgery, KH der Elisabethinen, Fadingerstr. 1, 4010 Linz, Austria. Phone: 437327676-0. Fax: 4373276764426. E-mail: florian.tomaselli@elisabethinen.or.at.
}

phages $(12,13)$. Recently, imaging procedures such as planar gamma scintigraphy (21) and positron emission tomography (39) were applied to support the definition of optimal dosing schedules for respiratory tract infections. A considerable disadvantage of these methods is their inability to discriminate between the free (and microbiologically active) and the bound (and microbiologically inactive) fractions of an antibiotic. Moreover, a clear determination of the concentration of an antibiotic in the interstitial space fluid of lung tissue, the very target site of infection, is not possible.

In vivo microdialysis enables the distributions of a large variety of chemical entities to be studied in many different clinical settings (20). Its particular advantage in the management of pulmonary infections lies in the potential opportunity to determine the free drug fraction in the interstitial space fluid of human lung tissue, the very target site of both bacterial infection and antibiotic action $(14,27)$. Based on these considerations and new data for noninfected lung tissue (14), we studied the technical feasibility of microdialysis and its ability to define the pharmacokinetic properties of antibiotics in interstitial pneumonic lung tissue in patients with pneumonia and undergoing surgery for consecutive episodes of metapneumonic empyema. The carbapenem meropenem was studied because it is a well-tolerated, broad-spectrum antibacterial agent which is well established for the empirical monotherapy of pneumonia, particularly in intensive care units $(11,33)$, and has no significant protein binding.

\section{MATERIALS AND METHODS}

The local ethics committee at the Medical Faculty of the University of Graz approved this study. All patients were given a detailed description of the study, and their written informed consent was obtained. The study was performed in 


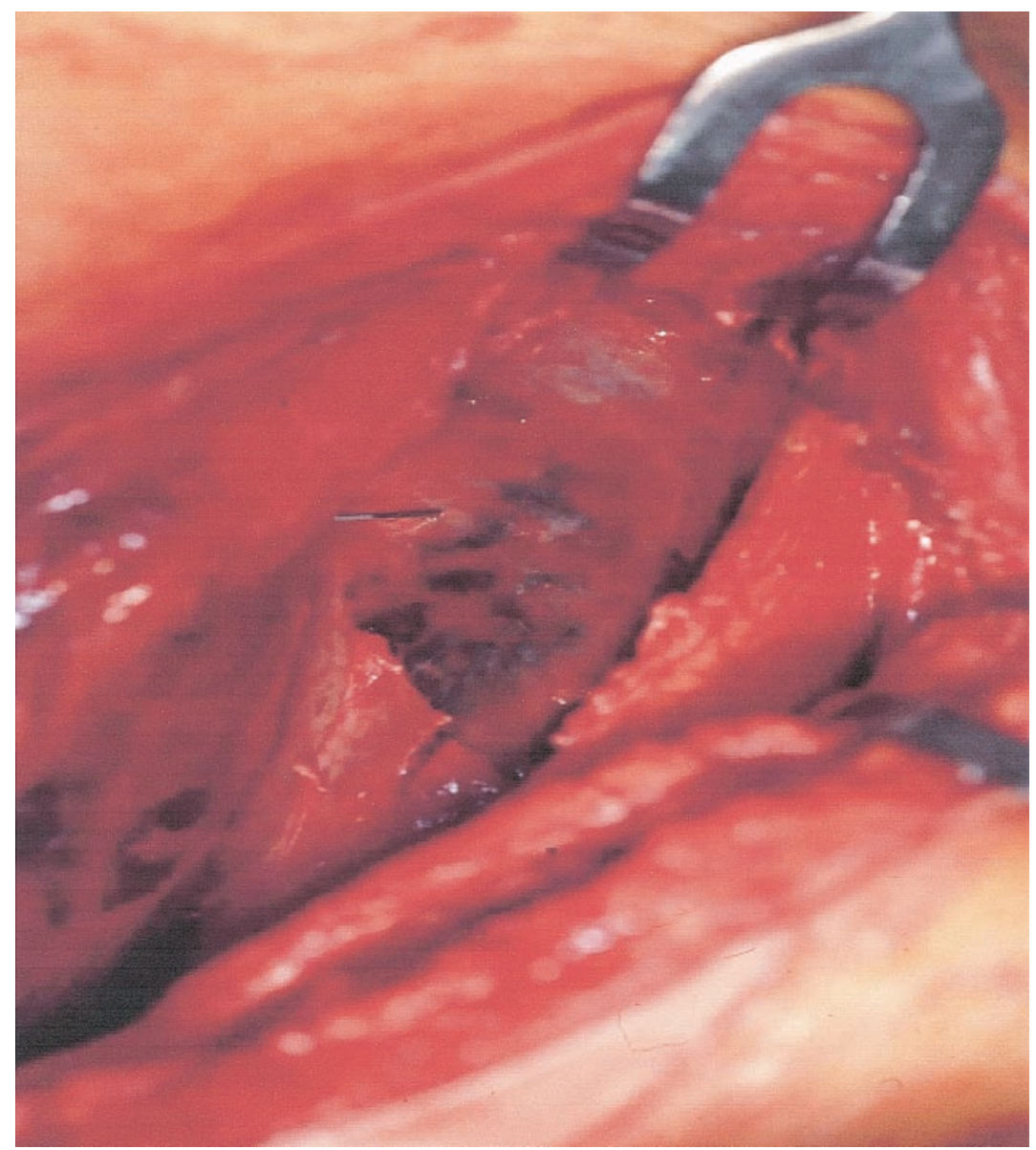

FIG. 1. Microdialysis probe placed percutaneously under direct vision well into pneumonic tissue at the end of the operation.

accordance with the Declaration of Helsinki and the Good Clinical Practice Guidelines of the European Commission.

Patients with sepsis (according to the criteria of the ACCP/SCCM Consensus Conference Committee) (7) due to pneumonia and metapneumonic pleural empyema that necessitated decortication over a lateral thoracotomy $(1,23,30)$ were eligible for inclusion in the study. The diagnosis of metapneumonic empyema was based preoperatively on the presence of intrapleural fluid accumulation and pulmonary opacities on chest roentgenograms; increased density of intrapleural fluid with loculations, pleural callosities, accentuated contrast medium enhancement, and pulmonary infiltrates on computed tomography scans; and pus recovered by thoracocentesis. Pleural fluid biochemical parameters were required to fall within the following limits: $\mathrm{pH},>7.10$; lactate dehydrogenase level, $>1,000 \mathrm{IU} /$ liter; glucose level, $<40 \mathrm{mg} / \mathrm{dl}$; protein level, $>2.5 \mathrm{~g} / \mathrm{dl}$; and white blood cell count, $>500 / \mathrm{ml}$.

The principles of microdialysis were described in detail previously $(22,26)$. In brief, microdialysis is based on the sampling of analytes from the extracellular space by means of a semipermeable membrane at the tip of a microdialysis probe. The probe is constantly perfused with a perfusion solution at a constant low flow rate. Once the probe is implanted into the tissue, substances present in the extracellular fluid will be filtered by diffusion out of the extracellular fluid and into the probe, resulting in a dialysate in the perfusion medium. By fractionation of collected samples, pharmacokinetic parameters for specific tissues can be determined.

For most analytes, the equilibrium between tissue extracellular fluid and the perfusion medium will be incomplete, so that the concentration in the extracellular fluid will be greater than the concentration in the perfusion medium. The factor interrelating the concentrations is termed recovery. The individual in vivo recovery, a calibration of the microdialysis probes, can be assessed by using the retrodialysis method $(20,26,34,38)$. This method is based on the assumption that the process of diffusion through the semipermeable membrane is equal in both directions.
We started antibiotic treatment with meropenem during the preoperative phase, including the interval of transfer and the diagnostic and functional evaluations of the patients. All patients received exclusively meropenem for the study phase. Patients received $1 \mathrm{~g}$ of meropenem (AstraZeneca, Vienna, Austria) intravenously (i.v.) as a 20 -min infusion every $8 \mathrm{~h}$. In each patient, two microdialysis probes (CMA, Stockholm, Sweden) were placed percutaneously under direct vision $2 \mathrm{~cm}$ apart well into pneumonic tissue (Fig. 1) at the end of the operation, directly before the planned fifth dose of meropenem. For reference tissue measurements, an additional probe was inserted into healthy skeletal muscle (contralateral pectoralis major muscle). By use of a microinfusion pump (Precidor; Infors-AG, Basel, Switzerland), the in situ probes were constantly perfused with Ringer's solution at a flow rate of $1.5 \mu \mathrm{l} / \mathrm{min}$. Microdialysis was started approximately $30 \mathrm{~min}$ after probe insertion, and the patients were monitored on the intensive care unit. For calibration, prior to the systemic administration of the study drug, the probes were perfused for $20 \mathrm{~min}$ with a solution of the drug, resulting in diffusion from the lumen into the tissue. The concentrations of the study drug in the lungs and in the muscle were adjusted for this individual recovery.

After a sufficient washout period for the system, meropenem was administered i.v. at a dose of $1 \mathrm{~g}$ over $20 \mathrm{~min}$. Sampling of dialysates and venous blood was performed at 20-min intervals for a period of $8 \mathrm{~h}$. Blood samples were collected in plastic tubes and were immediately centrifuged at $1,600 \times g$ for $5 \mathrm{~min}$. Serum and dialysate samples were shock frozen and stored over liquid nitrogen until analysis. Meropenem was assayed by using a previously published and validated high-pressure liquid chromatography method with a limit of detection of 1 $\mathrm{mg} /$ liter (28).

After the microdialysis procedure, all of the cannulas were removed.

Interstitial drug concentrations were calculated as sample concentration $\times$ (in vivo recovery) ${ }^{-1}$.

The following pharmacokinetic parameters were calculated by using the commercial software Kinetica version 3.0 with noncompartmental analysis: maximum 


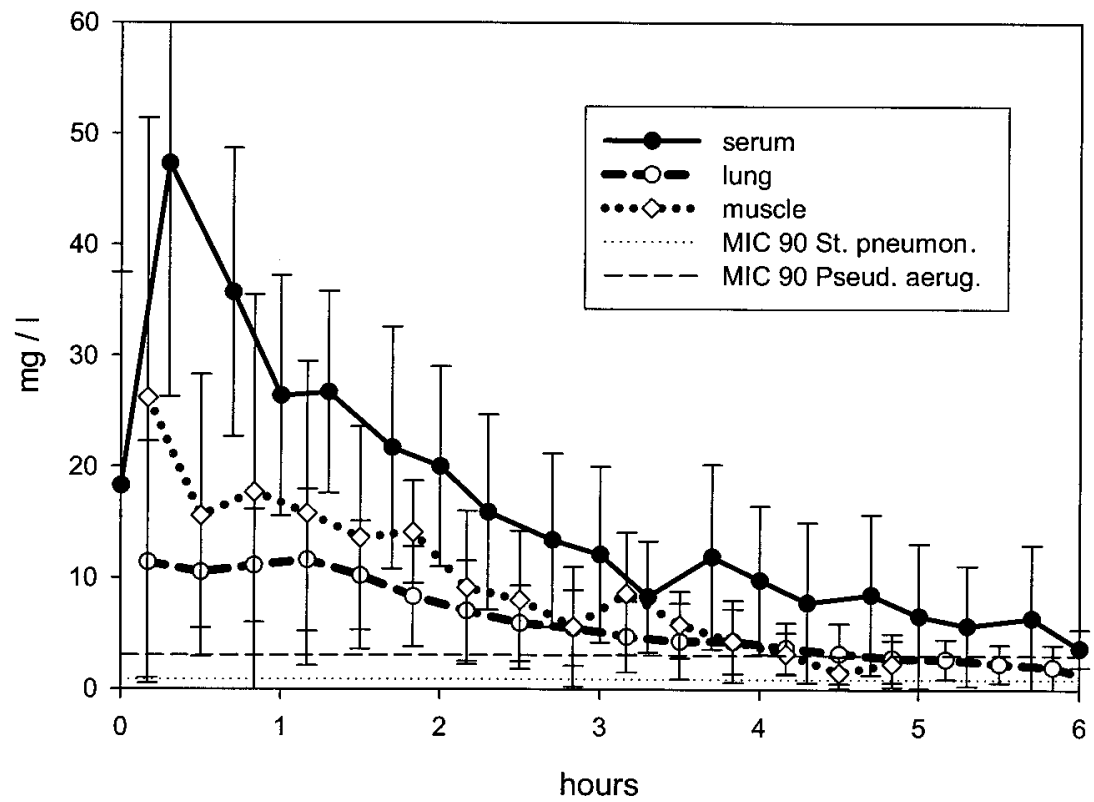

FIG. 2. Concentration-time profile for meropenem in infected lung interstitial fluid, healthy skeletal muscle, and serum after the fifth i.v. administration of $1 \mathrm{~g}$ of meropenem in a 20 -min infusion. St. pneumon., S. pneumoniae; Pseud. aerug., P. aeruginosa .

drug concentration $\left(C_{\max }\right)$, area under the concentration-time curve from 0 to $8 \mathrm{~h}$ (AUC), ratio of the AUC in the interstitium to the AUC in serum, time to $C_{\max }\left(T_{\max }\right)$, and elimination half-life.

Statistical tests were performed with untransformed as well as with log-transformed data and yielded identical results. Demographic and pharmacokinetic parameters were analyzed by descriptive methods (mean and standard deviation) as well as Wilcoxon's matched-pairs signed-rank test by using the commercial software StatView version 5.0 (SAS Institute Inc., Cary, N.C.).

\section{RESULTS}

From February 2002 to September 2002, seven male patients were included in the study. Patients had a mean age of 58.7 years (range, 30 to 75 years), a mean body weight of $72.3 \mathrm{~kg}$ (range, 68 to $87 \mathrm{~kg}$ ), and a mean body mass index of 22.6 (range, 19 to 25). Staphylococcus aureus, Streptococcus pneumoniae, Pseudomonas aeruginosa, Enterobacter aerogenes, and Klebsiella spp. were isolated as the causative pathogens by routine preoperative bronchoalveolar lavage and/or by diagnostic pleural puncture.

Because of technical reasons, in four of the seven patients, microdialysis samples were available from only one lung probe. For each of the other three patients, the mean of the results of the two probes was used in the calculations.
Figure 2 shows the concentration-time curves for meropenem in serum, lung, and skeletal muscle following the fifth i.v. infusion of meropenem. The MICs at which $90 \%$ of the organisms were inhibited in vitro $\left(\mathrm{MIC}_{90} \mathrm{~s}\right)$ for $S$. pneumoniae and $P$. aeruginosa are superimposed on Fig. 2. The major pharmacokinetic parameters for meropenem are summarized in Table 1. Meropenem rapidly penetrated infected lung tissue, reaching maximal concentrations in interstitial lung fluid of $11.4 \times 10.9 \mathrm{mg} /$ liter within a mean of $0.16 \mathrm{~h}$. The AUCs of meropenem in interstitial lung fluid and in muscle tissue were approximately two-fifths and three-fifths, respectively, that attained in serum. There was a statistically significant difference between the AUCs in lung fluid and serum $(P=0.018)$ but not between the AUCs in muscle tissue and serum.

No technical problems were encountered during the microdialysis procedure. The probes were removed after discontinuation of the perfusion (after a maximum of $11 \mathrm{~h}$ ). All patients were discharged within a median of 11.3 days (range, 8 to 23 days) without any recurrence of empyema (median follow-up, 10.5 months). No adverse effects related to microdialysis were observed.

TABLE 1. Pharmacokinetic parameters for meropenem (noncompartmental analysis) in serum, lung interstitial fluid, and skeletal muscle ${ }^{a}$

\begin{tabular}{|c|c|c|c|c|c|}
\hline Sample source & $\begin{array}{l}\text { Ratio of AUC in } \\
\text { interstitium to AUC } \\
\text { in serum }\end{array}$ & AUC $(\mathrm{mg} \cdot \mathrm{h} /$ liter $)$ & $\begin{array}{l}\text { Elimination } \\
\text { half-life }(\mathrm{h})\end{array}$ & $T_{\max }(\mathrm{h})$ & $C_{\max }(\mathrm{mg} /$ liter $)$ \\
\hline Serum & & $95.4 \pm 46.6$ & $2.2 \pm 1.25$ & $0.33^{b}$ & $47.3 \pm 21.0$ \\
\hline Lung & $0.41 \pm 0.21$ & $36.2 \pm 17.9^{c}$ & $1.73 \pm 0.754$ & 0.16 & $11.4 \pm 10.9$ \\
\hline Muscle & $0.60 \pm 0.40$ & $44.6 \pm 30.0$ & $1.27 \pm 0.581$ & 0.16 & $26.2 \pm 25.2$ \\
\hline
\end{tabular}

${ }^{a}$ Parameters were measured after the i.v. administration of meropenem at $1 \mathrm{~g}$ to seven patients with sepsis and undergoing lateral thoracotomy for pneumonia or metapneumonic pleural empyema. Except for $T_{\max }$, results are expressed as mean and standard deviation.

${ }^{b}$ At the end of the infusion.

${ }^{c}$ In a Wilcoxon signed-rank test comparison of results for lungs and serum, the $P$ value was $<0.05$. 


\section{DISCUSSION}

Antibiotic penetration to the target site is one of the most important determinants of the anti-infective drug effect. This is why, for both drug development and daily clinical routines, several trials have been performed to optimize the drug load at the site of infection.

In cases of lower respiratory tract infections, chemical analysis of sputum $(6,9,28)$ and analyses of tissue biopsy specimens and bronchoalveolar lavage fluid $(15,32)$, epithelial lining fluid $(4,35)$, and alveolar macrophages $(12,13)$ have been performed to obtain information about the penetration of antibiotics into the lungs $(3,16)$. However, the determination of concentrations of antibiotics in sputum is unreliable. Various studies demonstrated considerable variability in the absolute concentrations of antimicrobial agents in sputum, even when identical classes of antimicrobial agents were considered (6, 9, 28). Furthermore, although the determination of antibiotic concentrations in bronchial biopsy specimens is comparatively easy and shows better reproducibility than sputum analysis, it has limited clinical relevance, since it provides no information on the relative drug concentration in the interstitial fluid. Measurement of antibiotic concentrations in epithelial lining fluid involves many logistical problems, the major one being determination of the relative volume of epithelial lining fluid recovered by bronchoalveolar lavage.

Thus, none of the above-mentioned methods has enabled accurate insight into the pharmacokinetic profiles of the antibiotics in question, determination of drug concentrations in the interstitial space, or discrimination between the unbound and the bound drug fractions. Microdialysis is a promising in vivo technique for accurately measuring the free, unbound concentrations of various molecules $(22,25,37)$, ensuring continuous determination of concentrations in interstitial space fluid in a defined target tissue (31). This property allows relevant data on both pharmacokinetic profiles and pharmacologically active concentrations of substances to be obtained.

Accordingly, a Food and Drug Administration advisory committee recently acknowledged that microdialysis might be a potentially attractive approach for clinical studies on the tissue distributions of antimicrobial drugs $(10,24,36)$.

In the present study, the concept of microdialysis was successfully applied in a clinical setting-determining the free concentration of meropenem in the infected lung. Meropenem, characterized by a low level of protein binding, has good activity against a wide spectrum of pathogens frequently found in pleural metapneumonic empyema, such as $S$. aureus (methicillin susceptible; $\mathrm{MIC}_{90}, 0.25 \mathrm{mg} / \mathrm{liter}$ ), S. pneumoniae ( $\mathrm{MIC}_{90}, 0.06 \mathrm{mg} /$ liter), P. aeruginosa ( $\left.\mathrm{MIC}_{90}, 4.0 \mathrm{mg} / \mathrm{liter}\right), E$. aerogenes $\left(\mathrm{MIC}_{90}, 0.25 \mathrm{mg} / \mathrm{liter}\right)$, and Klebsiella pneumoniae ( $\mathrm{MIC}_{90}, 0.06 \mathrm{mg} /$ liter) (29). This agent has been successfully used as monotherapy for the treatment of bacterial lung infections in critically ill patients $(2,29)$.

In the present study, meropenem was administered at a dose of $1 \mathrm{~g}$ every $8 \mathrm{~h}$, as recommended by the manufacturer. At this dosage, sufficient concentrations of unbound meropenem were found in the interstitial space fluid of infected lung tissue in patients with metapneumonic empyema. The concentrations of meropenem in tissue were maintained above the $\mathrm{MIC}_{90}$ threshold for many clinically relevant pathogens, including $S$. aureus, S. pneumoniae, $P$. aeruginosa, E. aerogenes, and $K$.pneumoniae, for up to $6 \mathrm{~h}$ (i.e., $80 \%$ of the dosing interval). For $\beta$-lactam antibiotics, including the carbapenems, the time during which the antibiotic concentration remains above the MIC for the infecting pathogen has been found to positively correlate with good clinical outcome (R. Walker, D. Andes, R. Cinklin, S. Ebert, and W. Craig, Abstr. 34th Intersci. Conf. Antimicrob. Agents Chemother., abstr. A91, 1994). For meropenem, it is thought that maximal bacterial killing is attained when free drug levels are maintained above the MIC for the infecting pathogen for approximately $30 \%$ of the dosing interval (P. K. Dandekar, D. Maglio, C. A. Sutherland, C. H. Nightingale, and D. P. Nicolau, Abstr. 42nd Intersci. Conf. Antimicrob. Agents Chemother., abstr. A1388, 2002). The concentrations of meropenem in tissue were lower than those in serum because meropenem was not distributed homogeneously in this cohort. This point will be pursued in future studies by current and planned investigations.

Since both treatment failure and the development of resistant microorganisms may result from insufficient concentrations of antibiotics in tissues, the results from microdialysis can offer relevant information necessary for the future modification of dosages and intervals of application. From the technical point of view, microdialysis can be applied to pharmacokinetic studies dealing with target tissues and organs that are accessible to controlled puncture. Thoracic surgery in metapneumonic pleural empyema offers the ideal option, since microdialysis probes can be inserted under direct vision into the pneumonic tissue.

The procedure was well tolerated in our patients. Despite probes being in situ for up to $12 \mathrm{~h}$, no complications or side effects attributable to microdialysis could be observed. Even the removal of the microdialysis probes did not cause any pain to the patients.

In conclusion, microdialysis, which has been applied in a clinical setting - the infected human lung-is a practical and useful method for measuring the concentrations of antibiotics in lung interstitial fluid. With this method, meropenem has been shown to achieve good penetration into the lung interstitial fluid of patients with pneumonia and consecutive episodes of metapneumonic empyema.

\section{ACKNOWLEDGMENTS}

AstraZeneca supported this study.

The excellent technical assistance of Ing. I. Trebuch is gratefully acknowledged.

\section{REFERENCES}

1. Ali, I., and H. Unruh. 1990. Management of empyema thoracis. Ann. Thorac Surg. 55:355-359.

2. Alvarez Lerma, F. 2001. Efficacy of meropenem as monotherapy in the treatment of ventilator-associated pneumonia. J. Chemother. 13:70-81.

3. Baldwin, D. R., D. Honeybourne, and R. Wise. 1992. Pulmonary disposition of antimicrobial agents: in vivo observations and clinical relevance. Antimicrob. Agents Chemother. 36:1176-1180.

4. Baldwin, D. R., D. Honeybourne, and R. Wise. 1992. Pulmonary disposition of antimicrobial agents: methodological considerations. Antimicrob. Agents Chemother. 36:1171-1175

5. Bergeron, M. G. 1990. The changing bacterial spectrum and antibiotic choice, p. 197. In J. Deslaurier and L. K. Lacyuet (ed.), International trends in general thoracic surgery, vol. 6. The C.V. Mosby Co., St. Louis, Mo.

6. Bergogne-Berezin, E. 1981. Penetration of antibiotics into the respiratory tree. J. Antimicrob. Chemother. 8:171-174.

7. Bone, R. C., W. J. Sibbald, and C. L. Sprung. 1992. The ACCP-SCCM consensus conference on sepsis and organ failure. Chest 101:1481-1483. 
8. Chesnutt, M. S., and T. J. Prendergast. 2001. Pulmonary infections, p. 291-300. In L. W. Tierny, S. J. McPhee, and M. A. Papadakis (ed.), Current medical diagnosis and treatment. Lange Medical Publishing/McGraw-Hill Book Co., New York, N.Y.

9. Drusano, G. L. 1988. Role of pharmacokinetics in the outcome of infections Antimicrob. Agents Chemother. 32:289-297.

10. Food and Drug Administration. 1999. Guidance for industry. Developing antimicrobial drugs-general considerations for clinical trials. [Online.] Food and Drug Administration, U.S. Department of Health and Human Services, Washington, D.C. http://www.fda.gov/cder/guidance/2580dft.pdf.

11. Garau, J., J. Blanquer, L. Cobo, M. Darguerre, de Lattore, F. J., F. C. Leon, del Nogal, A. Net, and J. Rella. 1997. Prospective, randomized multicentre study of meropenem versus imipinem/cilastin as empiric monotherapy in severe nosocomial infections. Eur. J. Clin. Microbiol. Infect. Dis. 16:789-796.

12. Hand, W. L., N. L. King-Thompson, and T. H. Steinberg. 1983. Interactions of antibiotics and phagocytes. J. Antimicrob. Chemother. 12(Suppl. C):1-11.

13. Harf, R., G. Panteix, F. Desnottes, N. Diallo, and M. Leciereq. 1988. Spiramycin uptake by alveolar macrophages. J. Antimicrob. Chemother. 22(Suppl B):135-140.

14. Herkner, H., M. Müller, R. Kreischitz, N. Mayer, B. Frossard, M. Joukhadar, and C. Klein. 2002. Closed-chest microdialysis to measure antibiotic penetration into human lung. Am. J. Respir. Crit. Care Med. 165:273-276.

15. Honeybourne, D., J. M. Andrews, J. P. Ashby, R. Lodwick, and R. Wise. 1988 Evaluation of the penetration of ciprofloxacin and amoxycillin into the bronchial mucosa. Thorax 43:715-719.

16. Honeybourne, D., and D. R. Baldwin. 1992. The site concentrations of antimicrobial agents in the lung. J. Antimicrob. Chemother. 30:249-260.

17. Hyatt, J. M., P. S. McKinnon, G. S. Zimmer, and J. J. Schentag. 1995. The importance of pharmacokinetic/pharmacodynamic surrogate markers to outcome. Focus on antibacterial agents. Clin. Pharmacokinet. 28:143-160.

18. Jehl, F., P. Birckel, and H. Monteil. 1987. Hospital routine analysis of penicillins, third-generation cephalosporins and aztreonam by conventional and high-speed high-performance liquid chromatography. J. Chromatogr. 413:109-119.

19. Jehl, F., C. Muller-Serieys, V. de Larminat, H. Monteil, and E. BergogneBerezin. 1994. Penetration of piperacillin-tazobactam into bronchial secretions after multiple doses to intensive care patients. Antimicrob. Agents Chemother. 38:2780-2784.

20. Joukhadar, C., H. Derendorf, and M. Müller. 2001. Microdialysis, a novel tool for clinical studies of anti-infective agents. Eur. J. Clin. Pharmacol. 57:211-219.

21. Le Conte, P., G. Potel, P. Peltier, D. Horeau, Caillon, M. E. J., Juvin, M. F. Kergueris, D. Bugnon, and D. Baron. 1993. Lung distribution and pharmacokinetics of aerosolized tobramycin. Am. Rev. Respir. Dis. 147:1279-1282.

22. Lönnroth, P., P. A. Jansson, and U. Smith. 1987. A microdialysis method allowing characterization of intercellular water space in humans. Am. J. Physiol. 253:E228-E231.

23. Maier, A., W. Domej, U. Anegg, M. Woltsche, B. Fell, H. Pinter, and F. M Smolle-Juttner. 2000. CT or ultrasonically guided pigtail catheter drainage in multiloculated pleural empyema: a recommended procedure? Respirology 5:119-124.

24. Miller Reporting Company, Inc. 1989. Guidance documents on developing antimicrobial drugs. Food and Drug Administration, U.S. Department of Health and Human Services, Washington, D.C.

25. Müller, M., R. Schmid, A. Georgopoulos, A. Buxbaum, C. Wasicek, and H. G. Eichler. 1995. Application of microdialysis to clinical pharmacokinetics in humans. Clin. Pharmacol. Ther. 57:371-380.

26. Müller, M., O. Haag, T. Burgdorff, A. Georgopoulos, W. Weninger, B. Jansen, G. Stanek, H. Pehamberger, E. Aeneter, and H. G. Eichler. 1996. Characterization of peripheral-compartment kinetics of antibiotics by in vivo microdialysis in humans. Antimicrob. Agents Chemother. 40:2703-2709.

27. Müller, M. 2000. Microdialysis in clinical drug delivery studies. Adv. Drug Deliv. Rev. 45:255-269.

28. Pennington, J. E. 1981. Penetration of antibiotics into respiratory secretions. Rev. Infect. Dis. 3:67-73.

29. Pfaller, M. A., and R. N. Jones. 1997. A review of the in vitro activity of meropenem and comparative antimicrobial agents tested against 30,254 aerobic and anaerobic pathogens isolated world wide. Diagn. Microbiol. Infect. Dis. 28:157-163.

30. Renner, H., S. Gabor, H. Pinter, A. Maier, G. Friehs, and F. M. SmolleJüttner. 1998. Is aggressive surgery in pleural empyema justified? Eur. J. Cardiothorac. Surg. 14:117-122.

31. Ryan, D. M. 1993. Pharmacokinetics of antibiotics in natural and experimental superficial compartments in animals and humans. J. Antimicrob. Chemother. 31(Suppl. D):1-16.

32. Schentag, J. J. 1989. Clinical significance of antibiotic tissue penetration. Clin. Pharmacokinet. 16(Suppl. 1):25-31.

33. Sieger, B., S. J. Berman, R. W. Geckler, S. A. Farkas, et al. 1997. Empiric treatment of hospital-acquired lower respiratory tract infections with meropenem or ceftazidime with tobramycin: a randomized study. Crit. Care Med. 25:1663-1670.

34. Ståhle, L., P. Arner, and U. Ungerstedt. 1991. Drug distribution studies with microdialysis. III. Extracellular concentration of caffeine in adipose tissue in man. Life Sci. 49:1853-1858.

35. The BAL Cooperative Group Steering Committee. 1990. Bronchoalveolar lavage constituents in healthy individuals, idiopathic pulmonary fibrosis, and selected comparison groups. Am. Rev. Respir. Dis. 141:S166-S202.

36. The European Agency for the Evaluation of Medicinal Products. 2000. Evaluation of medicines for human use. Points to consider on pharmacokinetics and pharmacodynamics in the development of antibacterial medicinal products. CPMP/EWP/2655/99. [Online.] The European Agency for the Evaluation of Medicinal Products, London, United Kingdom. http://www.emea.eu .int/pdfs/human/ewp/265599en.pdf.

37. Ungerstedt, U. 1991. Microdialysis_-principles and applications for studies in animals and man. J. Intern. Med. 230:365-373.

38. Wang, Y., S. L. Wong, and R. J. Sawchuk. 1993. Microdialysis calibration using retrodialysis zeronet flux: application to a study of the distribution of zidovudine to rabbit cerebrospinal fluid and thalamus. Pharm. Res. 10:14111419.

39. Wollmer, P., N. B. Pride, C. G. Rhodes, A. Sanders, V. W. Pike, A. J. Palmer, D. J. Silvester, and R. H. Liss. 1982. Measurement of pulmonary erythromycin concentration in patients with lobar pneumonia by means of positron tomography. Lancet 2:1361-1364. 